\title{
POSSIBILITIES FOR OBSERVATIONS WITH THE INFRARED SPACE \\ OBSERVATORY OF EMISSION FROM SHOCK-HEATED DUST IN SNRs
}

\author{
J. Svestka \\ Prague Observatory, Prague, Czechoslovakia *
}

\begin{abstract}
The possibilities for observing infrared emission from shockheated dust in SNRs with the future Infrared Space Observatory (ISO) are illustrated with calculations of the ISOPHOT-P and ISOPHOT-C flux densities and integration times for radiation from six selected SNRs in eight wavelength bands between $4 \mu \mathrm{m}$ and $180 \mu \mathrm{m}$.
\end{abstract}

The flux densities of infrared radiation in eight wavelength bands $(4,25,35,50$, $75,105,140$, and $180 \mu \mathrm{m}$ ) from four selected galactic SNRs (Tycho, Kepler, Cas A and G292.0+1.8) and two extragalactic SNRs (1E0102.2-7219 in the SMC and an SNR in NGC4449) are estimated using results derived from IRAS observations (Braun 1985) and calculations of infrared emission from shock-heated dust (Draine 1981). The integration times are determined from the expected sensitivities of the multiband-multiaperture photopolarimeter (ISOPHOT-P) and the far infrared camera (ISOPHOT-C) (see Tables 1 and 2). The data for the extragalactic SNRs were obtained from Inoue et al. 1983, Raymond 1984, Blair et al. 1983 and Blair et al. 1984. The range of acceptable individual integration times was taken to be between 2 seconds and 1 hour, the total integration time up to 24 hours, and the minimum required signal-to-noise ratio equal to 10 .

With these restrictions it should be possible to map Cas A in all eight bands, Kepler in seven bands between $4 \mu \mathrm{m}$ and $140 \mu \mathrm{m}$, Tycho in six bands between $4 \mu \mathrm{m}$ and $105 \mu \mathrm{m}$, and G292.0+1.8 in five bands between $25 \mu \mathrm{m}$ and $105 \mu \mathrm{m}$. Similarly, observations of 1E0102.2-7219 in five bands between $25 \mu \mathrm{m}$ and $105 \mu \mathrm{m}$ and of the SNR in NGC4449 in the $25 \mu \mathrm{m}$ band should be possible. Finally, observations can be made with ISOPHOT-P with different apertures in the $4 \mu \mathrm{m}$ and $25 \mu \mathrm{m}$ bands for Cas $\mathrm{A}$ and Kepler, and in the $25 \mu \mathrm{m}$ band only for the other SNRs. Total observing time would be about 15.5 hours. The detailed results are given in Table 3 .

* A significant part of these calculations was made during the author's stay at the Max-Planck-Institut für Kernphysik, Heidelberg, F. R. G. 
Table 1 ISOPHOT-P (Multiband-Multiaperture Photopolarimeter)

Wavelength range ( $\mu \mathrm{m})$

Total number of spectral bands

Central wavelength ( $\mu \mathrm{m})$

Spectral resolution

Total number of apertures

Field of view (arc sec)

Polarization measurements

Min. detectable flux $(m J y)$

Photometry

$4 \mu m^{2}$ )

$25 \operatorname{sm}^{3}$ )

Polarimetry

$4 \mu \mathrm{m}^{2}$ )

$\left.25 \mu \mathrm{m}^{3}\right)$
$3 \ldots 30$

10

$4,6.5,10,16,25$, others TBD

$2.5,2.5,2.5,2.5,2.5$, others TBD

15

$5,8,12,20,30,40,60,80,110,150$, 180 , others TBD

3 grid polarizers with $0^{0}, 60^{\circ}, 120^{0}$

0.18

5.0

0.44

12.4

Table 2 ISOPHOT-C (Far Infrared Camera)

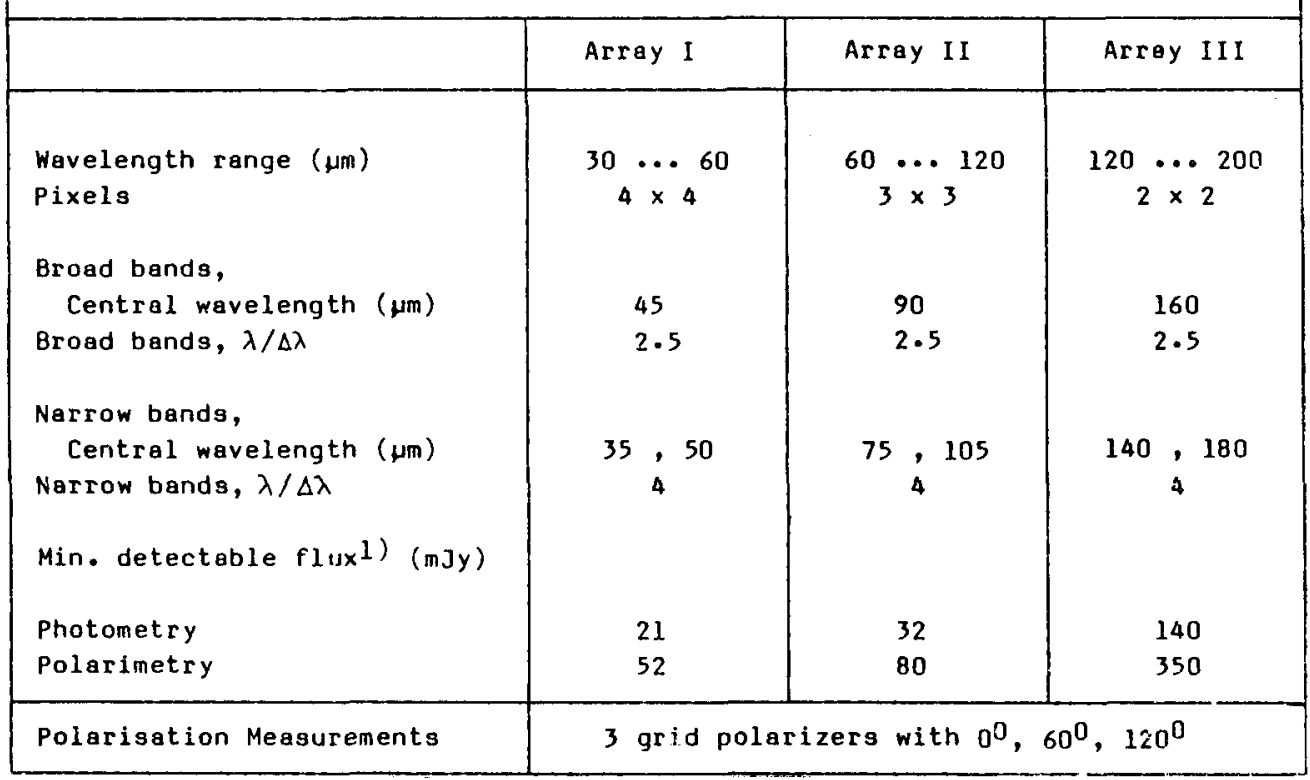

$\therefore$ Integration time $100 \mathrm{~s} ; \mathrm{S} / \mathrm{N}=10$; broadband filter

$2 \mathrm{NEP}=5 \cdot 10^{-18} \mathrm{~W} \cdot \mathrm{Hz}_{\mathrm{z}} \cdot 1 \mathrm{j}^{2}$

$3 \mathrm{NEP}=3 \cdot 10^{-17} \mathrm{~W} \cdot \mathrm{Hz}^{-1 / 2}$ 
Table 3

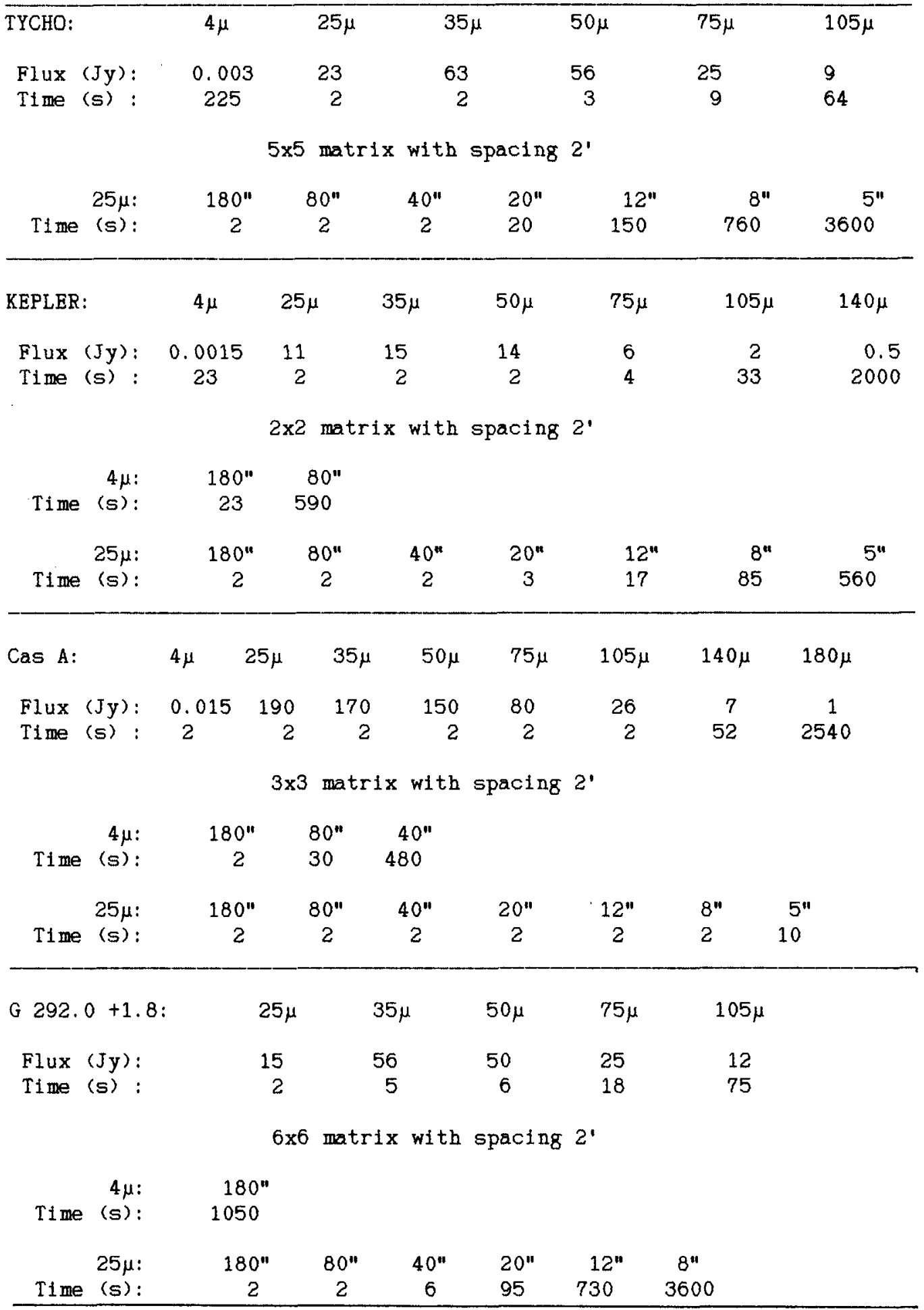


Table 3 (cont'd)

\begin{tabular}{|c|c|c|c|c|c|c|}
\hline 1E0102.2-7219: & $25 \mu$ & & & $50 \mu$ & $75 \mu$ & $105 \mu$ \\
\hline Flux (mJy): & 120 & 15 & & 140 & 60 & 20 \\
\hline Time (s) : & 2 & & & 3 & 30 & 260 \\
\hline $\begin{array}{r}25 \mu: \\
\text { T1me (s): }\end{array}$ & $\begin{array}{c}20^{n} \\
2\end{array}$ & $\begin{array}{c}12^{\prime \prime} \\
5\end{array}$ & $\begin{array}{c}8 " \\
23\end{array}$ & $150^{5^{n}}$ & & \\
\hline in NGC 4449 : & $25 \mu$ & & & & & \\
\hline Flux $(\mathbb{I} J y):$ & 3 & & & & & \\
\hline Time (s): & 280 & & & & & \\
\hline
\end{tabular}

\section{References}

Braun, R.,1985.Ph.D. Thesis, , Univ. of Leiden.

Draine, B. T.,1981. Astrophys. J., 245, 880.

Inoue, H., Koyama, K., and Tanaka, Y.,1983.Supernova Remnants and their X-ray Emission, , (ed. J. Danziger and P. Gorenstein) Reidel, Dordrecht p. 535.

Raymond, J. C.,1984. Ann. Rev. Astr. Astrophys., 22, 75.

Blair, W. P., Krishner, R. P., and Winkler, P. F.,1983. Astrophys. J., 272, 84.

Blair, W. P., Raymond, J. C., Fesen, R. A., and Gull, T. R.,1984. Astrophys. J., 279, 708. 